\title{
Community-acquired and hospital-acquired respiratory tract infection and bloodstream infection in patients hospitalized with COVID-19 pneumonia
}

Kirstine K. Søgaard ${ }^{1,2^{*}}$ (D) Veronika Baettig ${ }^{3}$, Michael Osthoff ${ }^{4,5}$, Stephan Marsch ${ }^{6}$, Karoline Leuzinger ${ }^{7}$, Michael Schweitzer ${ }^{1,2}$, Julian Meier ${ }^{2,8}$, Stefano Bassetti ${ }^{4,5}$, Roland Bingisser ${ }^{9}$, Christian H. Nickel ${ }^{9}$, Nina Khanna ${ }^{3}$, Sarah Tschudin-Sutter ${ }^{3,5}$, Maja Weisser ${ }^{3}$, Manuel Battegay ${ }^{3}$, Hans H. Hirsch ${ }^{3,7,10}$, Hans Pargger ${ }^{6}$, Martin Siegemund ${ }^{5,6}$ and Adrian Egli ${ }^{1,2^{*}}$

\begin{abstract}
Objectives: SARS-CoV-2 may cause acute lung injury, and secondary infections are thus relevant complications in patients with COVID-19 pneumonia. However, detailed information on community- and hospital-acquired infections among patients with COVID-19 pneumonia is scarce.

Methods: We identified 220 SARS-CoV-2-positive patients hospitalized at the University Hospital Basel, Switzerland (between 25 February and 31 May 2020). We excluded patients who declined the general consent $(n=12)$, patients without clinical evidence of pneumonia $(n=29)$, and patients hospitalized for $<24 \mathrm{~h}(n=17)$. We evaluated the frequency of community- and hospital-acquired infections using respiratory and blood culture materials with antigen, culture-based, and molecular diagnostics. For ICU patients, all clinical and microbial findings were reevaluated interdisciplinary (intensive care, infectious disease, and clinical microbiology), and agreement reached to classify patients with infections.
\end{abstract}

Results: In the final cohort of 162 hospitalized patients (median age 64.4 years (IQR, 50.4-74.2); 61.1\% male), 41 (25.3\%) patients were admitted to the intensive care unit, 34/41 (82.9\%) required mechanical ventilation, and 17 (10.5\%) of all hospitalized patients died. In total, 31 infections were diagnosed including five viral co-infections, 24 bacterial infections, and three fungal infections (ventilator-associated pneumonia, $n=5$; tracheobronchitis, $n=13$; pneumonia, $n=1$; and bloodstream infection, $n=6$ ). Median time to respiratory tract infection was 12.5 days (IQR, 8-18) and time to bloodstream infection 14 days (IQR, 6-30). Hospital-acquired bacterial and fungal infections were more frequent among ICU patients than other patients (36.6\% vs. $1.7 \%$ ). Antibiotic or antifungal treatment was administered in 71 (43.8\%) patients.

(Continued on next page)

\footnotetext{
* Correspondence: KirstineKobberoee.Soegaard@usb.ch; Adrian.Egli@usb.ch

${ }^{1}$ Clinical Bacteriology and Mycology, University Hospital Basel, Petersgraben 4, 4031 Basel, Switzerland

Full list of author information is available at the end of the article
}

(c) The Author(s). 2021 Open Access This article is licensed under a Creative Commons Attribution 4.0 International License, which permits use, sharing, adaptation, distribution and reproduction in any medium or format, as long as you give appropriate credit to the original author(s) and the source, provide a link to the Creative Commons licence, and indicate if changes were made. The images or other third party material in this article are included in the article's Creative Commons licence, unless indicated otherwise in a credit line to the material. If material is not included in the article's Creative Commons licence and your intended use is not permitted by statutory regulation or exceeds the permitted use, you will need to obtain permission directly from the copyright holder. To view a copy of this licence, visit http://creativecommons.org/licenses/by/4.0/ The Creative Commons Public Domain Dedication waiver (http://creativecommons.org/publicdomain/zero/1.0/) applies to the data made available in this article, unless otherwise stated in a credit line to the data. 
(Continued from previous page)

Conclusions: Community-acquired viral and bacterial infections were rare among COVID-19 pneumonia patients.

By contrast, hospital-acquired bacterial or fungal infections were frequently complicating the course among ICU patients.

Keywords: COVID-19, SARS-CoV-2, Bacterial secondary infections, Pneumonia, Sepsis

\section{Background}

Knowledge about community- and hospital-acquired infections in patients hospitalized with severe acute respiratory syndrome coronavirus 2 (SARS-CoV-2) infection is still limited. In the rapidly growing literature describing the clinical course of coronavirus disease (COVID-19), it has become evident that some patients suffer from acute respiratory distress syndrome (ARDS), systemic inflammation, and a prolonged disease course requiring sustained mechanical ventilation. Accordingly, COVID-19 patients per se would have a high risk of secondary infections [1]. Two recent meta-analyses $[2,3]$ found that few studies systematically reported frequency of secondary infections in COVID-19 patients and that the microbiological pathogens isolated and diagnostic methods used were most often not described. Overall, 7\% of hospitalized COVID-19 patients had a bacterial infection [2], but more than two thirds of patients were treated with antibiotics of which use of broadspectrum antibiotics was substantial [3]. This paradox emphasizes the relevance of antibiotic stewardshipalso in times of a pandemic-to avoid unnecessary empiric antibiotic treatment. Subsequent studies have reported that early bacterial infections are diagnosed in $2-3 \%$ of patients overall $[4,5]$. By contrast, late bacterial infections are much more frequent and may occur in a third of patients admitted to the intensive care unit (ICU), mainly as ventilator-associated and late onset infections [6]. Streptococcus pneumoniae and Staphylococcus aureus were the most frequent causes of community-acquired bacterial pneumonia, whereas Enterobacteriaceae and non-fermenters were main causes of hospital-acquired infections [4-6]. Bloodstream infections were reported to occur in around 5\% of patients of hospitalized COVID-19 pneumonia patients, which was more frequent than in a comparison cohort [7]. Among 78 patients requiring ICU stay, the 15-day cumulative risk of bloodstream infection was 25\% [8]. Moreover, multidrug-resistant bacteria consisted $12 \%$ of all isolated pathogens among Spanish COVID-19 patients, stressing the need for microbiological testing in order to direct antibiotic treatment [5].

In this study, we provide detailed information on diagnostics and occurrence of community-acquired and hospital- acquired viral, bacterial, and fungal infections among COVID-19 patients hospitalized at our hospital during the first pandemic wave.

\section{Methods}

In this descriptive study, we identified all consecutive adults with a first SARS-CoV-2-positive test hospitalized at Basel University Hospital during the pandemic phase (from 25 February to 31 May 2020). We excluded patients with elective admissions, who tested positive by routine screening and were asymptomatic, and patients without pneumonia (based on medical chart review documenting absence of respiratory symptoms and/or no pulmonary infiltrates). We further restricted the study cohort to patients with a minimal hospitalization duration of 24 hours. See Supplementary Material for criteria for SARS-CoV-2 testing and polymerase chain reaction (PCR) assay [9].

We then linked microbiology test results performed during the hospitalization, focusing on respiratory tract samples and blood-stream infections.

The University Hospital Basel is tertiary academic care centre in Switzerland with approximately 700 beds and 35,000 annual hospital admissions. The local ethics committee approved the study (EKNZ project ID 202000769).

\section{Additional microbiological diagnostics}

We assessed the occurrence of respiratory tract infection and bloodstream infection, by linking microbiological results from respiratory tract samples (including nasopharynx, sputum, tracheal secrete, and bronchoalveolar lavage fluid) and blood cultures taken in COVID-19 patients.

Additional viral diagnostics was performed with BIOFIRE $^{\oplus}$ FILMARRAY ${ }^{\circ}$ Respiratory 2 plus Panel PCR to achieve a rapid detection of other relevant viral respiratory pathogens (see Table S1 for examined pathogens) [9].

For the diagnostics of bacterial and fungal pathogens, culture plates including Columbia sheep blood agar (Becton Dickinson GmbH, BD), Colistin Nalidixic Acid blood agar for Gram positive bacteria (BD), and Haemophilus chocolate agar (bioMérieux) and MacConkey (BD) for Gram negatives were inoculated. In the case of additional requests, such as Legionella spp. or moulds, specific selective plates for the pathogens were inoculated (BMPA (BD) and Sabouraud Dextrose Agar (BD), 
respectively). The incubation times and conditions varied for specific pathogens. We used MALDI-TOF mass spectrometry (Bruker, microflex ${ }^{\mathrm{TM}}$ or MALDI Biotyper ${ }^{\text {TM}}$; MBT 8468 MSP Library, BDAL V9.0.0.0_78548468) for identification of bacterial or fungal species. In patients with suspicion of fungal infection, in-house real-time PCR for Aspergillus spp. or galactomannan antigen was supplementing culture.

Urine samples were analysed by Sofia ${ }^{\circ}$ Fluorescent Immunoassay (FIA) for Streptococcus pneumoniae antigen and by Quidel Corporation ${ }^{\circ}$, San Diego, CA, USA, for the Legionella pneumophila serogroup 1.

Blood cultures (aerobic and anaerobic) were incubated for a maximum of 6 days (BacT/Alert ${ }^{\circ}$ with Virtuo incubators, bioMérieux). The initial pathogen identification was done using MALDI-TOF MS directly from positive culture bottles [10] or BIOFIRE FILMARRAY BCID Panel PCR (bioMérieux, Lyon, France), and after subculturing confirmed using MALDI-TOF MS. For resistance testing, we used VITEK2 (bioMérieux) microdilution, Etest strips (Liofilchem ${ }^{\circ}$, Roseto degli Abruzzi, Italiy), or Sensititre $^{\ominus}$ YeastOne $^{\bullet}$ (Thermo Fischer Scientific, Altrincham, UK).

\section{Community-acquired infection}

Viral co-infection was defined as detection of another viral respiratory pathogen concurrent to SARS-CoV-2 diagnosis. Community-acquired bacterial pneumonia was defined as a microbiology-confirmed pneumonia diagnosed concurrent with SARS-CoV-2 infection or within less than $48 \mathrm{~h}$ of hospital admission [11]. Community-acquired bloodstream infection was defined as identification of a pathogen from a blood culture taken within $48 \mathrm{~h}$ of hospitalization.

\section{Hospital-acquired infection}

Hospital-acquired infection was defined as secondary infection occurring more than $48 \mathrm{~h}$ after hospitalization for SARS-CoV-2. Hospital-acquired pneumonia (HAP) and ventilator-associated pneumonia (VAP) were defined as pneumonias occurring $48 \mathrm{~h}$ or more after hospitalization or endotracheal intubation, respectively [11]. For possible VAP diagnosis, indicators of worsening oxygenation $\left(\mathrm{FiO}_{2}\right.$ value increase by $\geq 0.20$ or PEEP value increase by $\geq 3 \mathrm{~cm} \mathrm{H} \mathrm{H}_{2} \mathrm{O}$ ) over $48 \mathrm{~h}$ and purulent respiratory secretions and/or a positive culture for a respiratory pathogen was required [12]. ICU patients with clinical signs of a secondary infection (e.g. new fever, increased purulent tracheal secretion, bronchoscopy with purulent or haemorrhagic secretion/aspiration or radiology with consolidations consistent with bacterial pneumonia), but without microbiological evidence, were considered as culture-negative respiratory infections.
We defined hospital-acquired bloodstream infection as identification of a pathogen from a blood culture taken $48 \mathrm{~h}$ or more after hospitalization. An infectious disease specialist evaluated all patients with a positive blood culture (at the time of the positive culture) determining the clinical relevance.

\section{Antibiotic treatment}

We retrieved information on antibiotic and antifungal medication administrated during hospitalization from the electronic medical record. Only systemic administrations with duration of more than $24 \mathrm{~h}$ were considered.

\section{Evaluation of ICU patients}

Two senior medical doctors (intensive care specialist, MS, and infectious disease specialist, VB) independently performed a re-evaluation of all clinical and microbial findings for ICU patients, in order to identify cases with VAP, tracheobronchitis, and blood-stream infection.

\section{Statistical analysis}

Patients were followed for the occurrence of respiratory tract infections until discharge, death, or end of followup (30 June 2020, i.e. a minimum of 30 days), whichever came first. We tabulated gender and median age (with interquartile range, IQR) and calculated frequency of mechanical ventilation, and extracorporeal membrane oxygenation (ECMO). We calculated duration of symptoms before hospitalization and length of stay (median, IQR). We examined the occurrence of co-and secondary infections (pneumonia, tracheobronchitis, and bloodstream infection) and described use of antibiotics and antifungal therapy. Statistical analyses were performed using STATA 12.0 (StataCorp LP, College Station, TX, USA).

\section{Results}

From 25 February to 31 May 2020, 1073 (7.8\%) out of 13,834 persons tested for SARS-CoV-2 at our hospital were positive. Of these, 220 (21\%) were hospitalized. Twelve patients declined general consent and were not further considered. We also excluded 17 patients admitted for elective surgery or other medical condition (test positive but asymptomatic), 12 SARS-CoV-2-positive patients without signs of a pneumonia, and 17 patients with a hospitalization duration $<24 \mathrm{~h}$ (Fig. 1). Among the remaining 162 patients, median age was 64.4 years (IQR, 50.4-74.2), 99 (61.1\%) were males, and median length of stay was 7.7 days (IQR, 4.1-12.3). Median duration of symptoms before hospitalization was 7.6 days (IQR, 4.6-11.5). Among the 162 patients, 41 (25.3\%) required ICU admission, and 17 (10.5\%) died (Table 1). Characteristics and outcomes of the excluded patients are described in the Supplementary Material. 


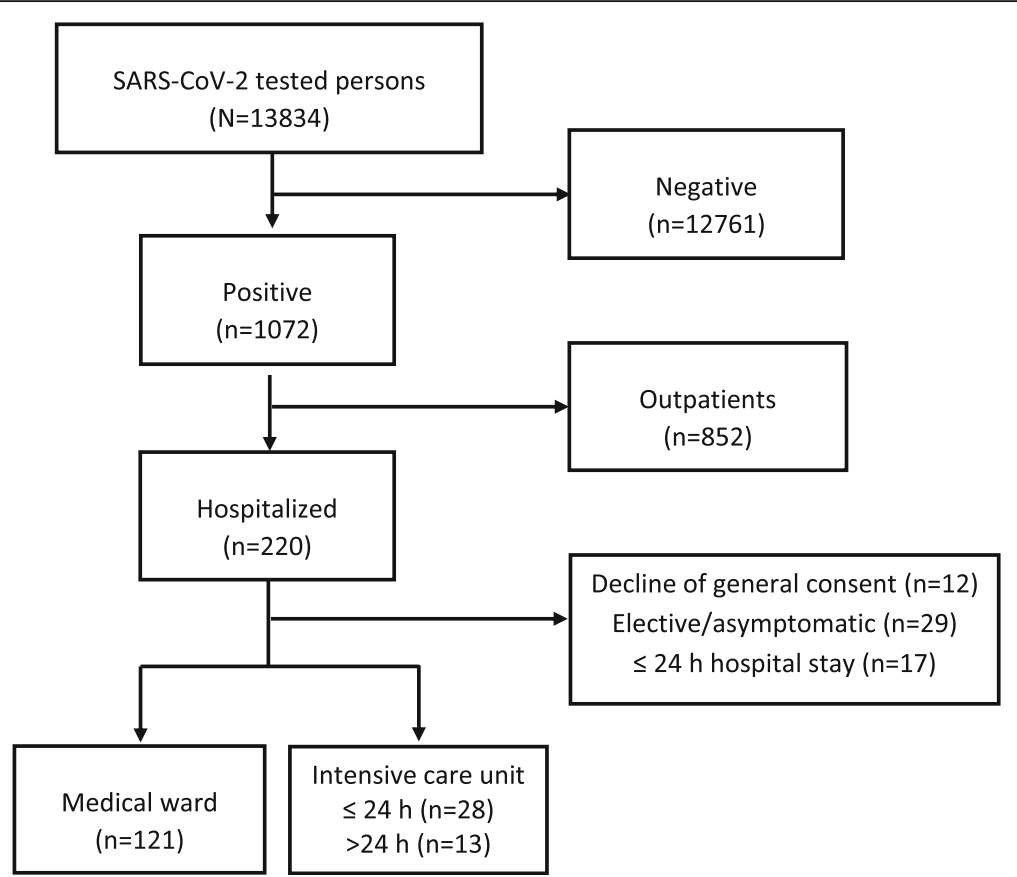

Fig. 1 Flowchart depicting the cohort

Table 1 Characteristics and outcomes of 162 SARS-CoV-2 hospitalized patients, according to need of intensive care

\begin{tabular}{|c|c|c|c|}
\hline & All $(n=162)$ & Non-ICU $(n=121)$ & ICU-patients $(n=41)$ \\
\hline Age, median (IQR) & $64.4(50.4-74.2)$ & $62.6(49.8-74.8)$ & $64.8(54.7-72.1)$ \\
\hline Males, $n(\%)$ & $99(61.1)$ & $68(56.2)$ & $31(75.6)$ \\
\hline Symptom duration before hospitalization, median days (IQR) ${ }^{a}$ & $7.6(4.6-11.5)$ & $7.5(4.1-10.9)$ & $9.2(6.6-13.3)$ \\
\hline Length of stay, median days (IQR) & $7.7(4.1-12.3)$ & $6.0(4.0-9.9)$ & $14.5(9.5-28.1)$ \\
\hline Mechanical ventilation, $n$ (\%) & $34(21.0)$ & - & $34(82.9)$ \\
\hline Extracorporeal membrane oxygenation (ECMO), $n$ (\%) & $2(1.2)$ & - & $2(4.9)$ \\
\hline Antibiotic or antifungal treatment & $71(43.8)$ & $35(28.9)$ & $36(87.8)$ \\
\hline Mortality, $n$ (\%) & $17(10.5)$ & $9(7.4)$ & $8(19.5)$ \\
\hline Community-acquired infections, $n$ patients (\%) & $6(3.7)$ & $4(3.3)$ & $2(4.9)$ \\
\hline Viral co-infection, $n$ events (\%) & $5(3.1)$ & $4(3.3)$ & $1(2.4)$ \\
\hline Bacterial pneumonia and bacteraemia, $n$ events (\%) & $1(0.6)$ & 0 & $1(2.4)$ \\
\hline Hospital-acquired infections, $n$ patients (\%) & $17(10.5)$ & $2(1.7)$ & $15(36.6)$ \\
\hline Bacterial and/or fungal infection, $\mathrm{n}$ events (\%) & $25(15.4)$ & $2(1.7)$ & $23(56.1)$ \\
\hline Bacterial infection, $n$ events (\%) & $23(13.6)$ & $2(1.7)$ & $21(51.2)$ \\
\hline -Ventilator-associated pneumonia (VAP) ${ }^{b, c}$ & $5(3.1)$ & 0 & $5(12.2)$ \\
\hline -Tracheobronchitis ${ }^{c}$ & $13(8.0)$ & 0 & $13(31.7)$ \\
\hline -Non-ventilator-associated pneumonia & $1(0.6)$ & $1(0.8)$ & 0 \\
\hline -Hospital-acquired bacteraemia & $4(2.5)$ & $1(0.8)$ & $3(7.3)$ \\
\hline Fungal infection, $n$ events (\%) & $3(1.9)$ & 0 & $3(7.3)$ \\
\hline -Ventilator-associated pneumonia (VAP) b, c & $2(1.2)$ & - & $2(4.9)$ \\
\hline -Hospital-acquired candidemia & $1(0.6)$ & - & $1(2.4)$ \\
\hline
\end{tabular}




\section{Completeness of microbiology testing}

Among the 162 included patients, 87 (53.7\%) were examined with BIOFIRE ${ }^{\circ}$ FILMARRAY $^{\circ}$ Respiratory 2 plus Panel, and 35 (21.6\%) had one or more respiratory samples for culture. Urinary antigen test for Legionella pneumophila and Streptococcus pneumoniae was performed in $60(37.0 \%)$ and $48(29.6 \%)$ patients, respectively. Finally, 127 (78.4 \%) had one or more blood cultures taken. Completeness of testing was higher for patients with an ICU admission (63.4\% respiratory samples for culturing, 68.3\% urine antigen for Legionella pneumophila, $56.1 \%$ urine antigen for Streptococcus pneumoniae, and $95.1 \%$ had blood culture drawn) (Table 2).

\section{Community-acquired infections}

Co-detection of other respiratory viral or bacterial pathogens was rare among the 162 hospitalized patients. In five (3.1\%) patients, another community-acquired respiratory virus was detected (Table 1 and Table S1). One patient was transferred from another hospital with Streptococcus pneumoniae pneumonia and bacteraemia.

\section{Hospital-acquired infections}

We observed no hospital-acquired viral infections. However, a total of $14(8.3 \%)$ patients had growth of relevant pathogens in their respiratory samples and by clinical evaluation a secondary bacterial infection (noted in the patient record). The spectrum of pathogens was dominated by gram-negative rods, but importantly also included two Aspergillus fumigatus (Table 3). Only one multi-drug resistant pathogen (Acinetobacter baumannii, Oxa-23) was isolated in a case transferred from a hospital abroad. Other susceptibility tests were in agreement with the low occurrence of multi-drug resistant pathogens in Switzerland. Median time to infection was 12.5 days (IQR 8-18). Five patients (3.0\%) were diagnosed with hospital-acquired bloodstream infection. One patient had Escherichia coli bacteraemia (and preceding Escherichia coli VAP); one patient had Pseudomonas aeruginosa bacteraemia and urinary tract infection; and two patients had catheter-associated sepsis with Candida albicans and Staphylococcus epidermidis, respectively. Finally, one patient had a Citrobacter koseri bacteraemia of unknown origin. Median time to bloodstream infection was 14 days (IQR, 6-30). Additional 15 patients had positive blood cultures that were deemed a contamination (see Table 2 and Table S2 for all microorganism cultured).

\section{Antibiotic and antifungal treatment}

In total, $71 / 162(43.8 \%)$ patients received one or more antibiotics or antifungals during the hospitalization. The most frequent antibiotics were amoxicillin with clavulanic acid $(n=36,22.2 \%)$, piperacillin/tazobactam $(n=30$, $18.5 \%)$, and ceftriaxone $(n=14,8.6 \%)$. In addition, seven (5.8\%) patients were treated with an azole or echinocandin (Table 4). In total, 48 patients were treated with one antibiotic only, whereas 23 patients were treated with two or more (up to six) different antibiotics or antimycotics during the hospitalization.

\section{Subcohort of patients admitted to ICU $(n=41)$}

Patients requiring ICU admission for COVID-19 pneumonia had similar median age as the overall cohort, but the proportion of males were higher $(75.6 \%$ vs. $61.1 \%)$. Median duration of symptoms before hospitalization was 9.2 days (IQR, 6.6-13.3), and median length of hospital stay was 14.5 days (IQR, 9.5-28.1). All patients had typical radiological findings of COVID-19 pneumonia at admission. Out of the 41 patients, 34 (82.9\%) required mechanical ventilation, and two patients ECMO. Eight patients died (19.5\%) during ICU admission. Two patients had co-detection of another respiratory pathogen at time of SARS-CoV-2 diagnosis; one had Parainfluenza

Table 2 Completeness of microbiology testing and frequency of positive test result among 162 SARS-CoV-2 hospitalized patients

\begin{tabular}{|c|c|c|c|c|c|c|}
\hline & \multicolumn{2}{|l|}{ All $(n=162)$} & \multicolumn{2}{|c|}{ Non-ICU $(n=121)$} & \multicolumn{2}{|c|}{ ICU-patients $(n=41)$} \\
\hline & $\begin{array}{l}\text { Individuals } \\
\text { tested, } \boldsymbol{n}(\%)\end{array}$ & $\begin{array}{l}\text { Positive test/ } \\
\text { tested, } n(\%)\end{array}$ & $\begin{array}{l}\text { Individuals } \\
\text { tested, } n \text { (\%) }\end{array}$ & $\begin{array}{l}\text { Positive test/ } \\
\text { tested, } n(\%)\end{array}$ & $\begin{array}{l}\text { Individuals } \\
\text { tested, } n(\%)\end{array}$ & $\begin{array}{l}\text { Positive test/ } \\
\text { tested, } n(\%)\end{array}$ \\
\hline $\begin{array}{l}\text { BIOFIRE }^{\oplus} \text { FILMARRAY }^{\circledast} \\
\text { Respiratory } 2 \text { plus Panel }\end{array}$ & $87 / 162(53.7)$ & $5 / 87(5.7)$ & $62 / 121(51.2)$ & $4 / 62(6.5)$ & 25/41 (61.0) & $1 / 25(4.0)$ \\
\hline $\begin{array}{l}\text { Respiratory culture } \\
\text { ( } n=184 \text { samples) }\end{array}$ & 35/162 (21.6) & 19/35 (54.3) & 9/121 (7.4) & $4 / 9(44.4)$ & 26/41 (63.4) & $15 / 26(57.7)$ \\
\hline $\begin{array}{l}\text { Legionella pneumophila } \\
\text { (urinary antigen) }\end{array}$ & 60/162 (37.0) & 0 & $32 / 121(26.4)$ & 0 & 28/41 (68.3) & 0 \\
\hline $\begin{array}{l}\text { Streptococcus pneumonia } \\
\text { (urinary antigen) }\end{array}$ & 48/162 (29.6) & $1 / 48(2.1)$ & 25/121 (20.7) & 0 & 23/41 (56.1) & $1 / 23(4.3)$ \\
\hline $\begin{array}{l}\text { Blood culture } \\
\text { ( } n=1110 \text { bottles) }\end{array}$ & $127 / 162(78.4)$ & 20/127 (15.7) & $88 / 121(72.7)$ & $11 / 88(12.5)$ & 39/41 (95.1) & 10/39 (25.6) \\
\hline
\end{tabular}

${ }^{a}$ A positive test result was not equal to clinical infection

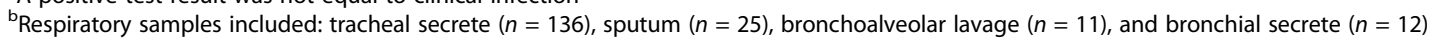


Table 3 Detected pathogens among patients with clinical signs of respiratory tract infection or bloodstream infection

\begin{tabular}{|c|c|c|c|}
\hline & $\begin{array}{l}\text { All }(n=162) \\
n(\%)\end{array}$ & $\begin{array}{l}\text { Non-ICU }(n=121) \\
n(\%)\end{array}$ & $\begin{array}{l}\text { ICU-patients }(n=41) \\
n(\%)\end{array}$ \\
\hline Community-acquired pneumonia and bacteraemia, $n(\%)$ & $1(0.6)$ & 0 & $1(2.4)$ \\
\hline Streptococcus pneumoniae ${ }^{a}$ (day 1) & $1(0.6)$ & 0 & $1(2.4)$ \\
\hline Hospital-acquired pneumonia, n (\%) & $1(0.6)$ & $1(0.8)$ & 0 \\
\hline Haemophilus influenzae (day 6) & $1(0.6)$ & $1(0.8)$ & 0 \\
\hline Ventilator-associated pneumonia (among 34 patients), n (\%) & - & - & $5(14.7)$ \\
\hline Acinetobacter baumannii MDR/ Aspergillus fumigatus (day 20) & - & - & $1(2.9)$ \\
\hline Escherichia colib (day 7) & - & - & $1(2.9)$ \\
\hline Enterobacter cloacae group ${ }^{c}$ (day 10) & - & - & $1(2.9)$ \\
\hline Aspergillus fumigatus (day 13) & - & - & $1(2.9)$ \\
\hline Culture negative (day 10) & - & - & $1(2.9)$ \\
\hline Hospital-acquired tracheobronchitis, n (\%) & $13(8.0)$ & 0 & $13(39.0)$ \\
\hline Staphylococcus aureus ${ }^{\text {d }}$ (day 3) & $1(0.6)$ & 0 & $1(2.4)$ \\
\hline Staphylococcus aureus ${ }^{\mathrm{d}} /$ Klebsiella aerogenes $^{e}$ (day 15) & $1(0.6)$ & 0 & $1(2.4)$ \\
\hline Escherichia coli (day 17) & $1(0.6)$ & 0 & $1(2.4)$ \\
\hline Klebsiella aerogenes (day 12) & $1(0.6))$ & 0 & $1(2.4)$ \\
\hline Klebsiella pneumoniae/Proteus mirabilis (day 18) & $1(0.6)$ & 0 & $1(2.4)$ \\
\hline Klebsiella variicola (day 20) & $1(0.6)$ & 0 & $2(4.9)$ \\
\hline Serratia marcescens ${ }^{\complement}$ (day 5 and day 25 ) & $1(0.6)$ & 0 & $2(4.9)$ \\
\hline Pseudomonas aeruginosa (day 4 and day 13) & $2(1.2)$ & 0 & $2(4.9)$ \\
\hline Stenotrophomonas maltophilia ${ }^{e}$ (day 24) & $1(0.6)$ & 0 & $1(2.4)$ \\
\hline Culture negative (day 4) & $1(0.6)$ & 0 & $1(2.4)$ \\
\hline Hospital-acquired bloodstream infection, n (\%) & $5(3.1)$ & 0 & $4(9.8)$ \\
\hline Staphylococcus epidermidis (day 44) & $1(0.6)$ & 0 & $1(2.4)$ \\
\hline Escherichia colib (day 16) & $1(0.6)$ & 0 & $1(2.4)$ \\
\hline Citrobacter koseri (day 4) & $1(0.6)$ & $1(0.8)$ & 0 \\
\hline Pseudomonas aeruginosa (day 8) & $1(0.6)$ & 0 & $1(2.4)$ \\
\hline Candida albicans (day 14) & $1(0.6)$ & 0 & $1(2.4)$ \\
\hline
\end{tabular}

${ }^{a}$ This patient was diagnosed with blood-stream infection at another hospital and transferred to Basel University hospital

${ }^{\mathrm{b}}$ This patient first presented with VAP and later with bacteraemia

'This patient had two separate episodes with same pathogen

${ }^{\mathrm{d}}$ Methicillin susceptible

${ }^{e}$ This patient had two separate episodes with different pathogens

virus and another had community-acquired pneumonia and bacteraemia with Streptococcus pneumonia. A total of 22 hospital-acquired infections were diagnosed among 16 patients, including five cases of VAP, 13 episodes of tracheobronchitis, and four bloodstream infections (Table 1 and Table 3). Importantly, these infections also covered two invasive Aspergillus fumigatus infections. In one patient, Aspergillus fumigatus was cultured (tracheal aspirate, day 13), whereas the galactomannan antigen test in blood was negative. However, autopsy confirmed multiorgan invasive aspergillosis. In a second patient, $A s$ pergillus fumigatus was cultured (tracheal aspirate, day 20) and confirmed by an Aspergillus-specific PCR (bronchial secrete). Both patients showed a respiratory deterioration before the microbiological diagnosis, and of note, they were not immunosuppressed nor treated with tocilizumab. The majority of patients $(n=36$, $87.8 \%)$ were treated with antibiotic and/or antifungal therapy. Among 24 patients (58.5\%) with no clinical signs of bacterial or fungal secondary infections during ICU stay, 19 (79.2\%) were treated with antibiotics.

\section{Discussion}

We provide an in-depth analysis of community- and hospital-acquired viral, bacterial, and fungal infections among 162 patients hospitalized with COVID-19 pneumonia at University Hospital Basel, Switzerland. We found that co-infections at time of admission were rare 
Table 4 Antibiotic and antimycotic treatment among 71 of 162 hospitalized SARS-CoV-2 patients

\begin{tabular}{|c|c|c|c|}
\hline Medication (ATC code) & $\begin{array}{l}\text { All }(n=162)^{\mathrm{a}} \\
n(\%)\end{array}$ & $\begin{array}{l}\text { Non-ICU }(n=121) \\
n(\%)\end{array}$ & $\begin{array}{l}\text { ICU-patients }(n=41) \\
n(\%)\end{array}$ \\
\hline One or more antibiotic or antifungal treatments & $71 / 162(43.8)$ & $35 / 121(28.9)$ & $36 / 41(87.8)$ \\
\hline \multicolumn{4}{|l|}{ Penicillins +/- beta-lactamase inhibitors } \\
\hline Amoxicillin (J01CA04) & $1(0.6)$ & 0 & $1(2.4)$ \\
\hline Amoxicillin and clavulanic acid (J01CR02) & $36(22.2)$ & $18(14.9)$ & $18(43.9)$ \\
\hline Piperacillin/tazobactam (J01CR05) & $30(18.5)$ & $10(8.3)$ & $20(48.8)$ \\
\hline \multicolumn{4}{|l|}{ Carbapenems } \\
\hline Meropenem (J01DH02) & $16(9.9)$ & $1(0.8)$ & $15(36.6)$ \\
\hline Imipenem (J01DH51) & $1(0.6)$ & 0 & $1(2.4)$ \\
\hline \multicolumn{4}{|l|}{ Cefalosporins } \\
\hline Ceftriaxone (J01DD04) & $14(8.6)$ & $8(6.6)$ & $6(14.6)$ \\
\hline Cefepime (J01DE01) & $4(2.5)$ & $1(0.8)$ & $3(7.3)$ \\
\hline Cefazolin (J01DB04) & $1(0.6)$ & 0 & $1(2.4)$ \\
\hline \multicolumn{4}{|l|}{ Quinolones } \\
\hline Ciprofloxacin (J01MA02) & $1(0.6)$ & $1(0.8)$ & 0 \\
\hline \multicolumn{4}{|l|}{ Sulfonamides with trimethoprim } \\
\hline Sulfamethoxazole with trimethoprim (J01EE01) & $3(1.9)$ & $2^{\mathrm{b}}(1.7)$ & $1(2.4)$ \\
\hline \multicolumn{4}{|l|}{ Aminoglycosides } \\
\hline Tobramycin (J01GB01) & $1(0.6)$ & 0 & $1(2.4)$ \\
\hline \multicolumn{4}{|l|}{ Polymyxines } \\
\hline Colistin (J01XB01) & $1(0.6)$ & 0 & $1(2.4)$ \\
\hline \multicolumn{4}{|l|}{ Glycopeptides } \\
\hline Vancomycin (J01XA01) & $2(1.2)$ & $2^{c}(1.7)$ & 0 \\
\hline \multicolumn{4}{|l|}{ Other antibacterials } \\
\hline Daptomycin (J01XX09) & $3(1.9)$ & 0 & $3(7.3)$ \\
\hline \multicolumn{4}{|l|}{ Antimycotics } \\
\hline Fluconazole (J02AC01) & $1(1.2)$ & 0 & $1(2.4)$ \\
\hline Caspofungin (J02AX04) & $3(1.9)$ & $1(0.8)$ & $2(4.9)$ \\
\hline Anidulafungin (J02AX06) & $1(0.6)$ & 0 & $1(2.4)$ \\
\hline Voriconazole (J02AC03) & $2(1.2)$ & 0 & $2(4.9)$ \\
\hline
\end{tabular}

Only treatment administered more than $24 \mathrm{~h}$ was considered as relevant

${ }^{a}$ Several patients received one or more antibiotics

${ }^{b}$ Sulfamethoxazole with trimethoprim was administered as prophylaxis in immunocompromised patients

'Vancomycin was administered peroral for treatment of Clostridioides difficile infection

among the patients. By contrast, secondary pulmonary infections and/or bloodstream infections were frequent, in particular among patients requiring ICU admission. Enterobacteriaceae were the most frequent pathogens detected, but also non-fermenters and Aspergillus fumigatus were identified causes of pulmonary infection.

Several clinical factors have been identified as prognostic factors for poor outcome of COVID-19 [13-15]. However, as demonstrated in two recent meta-analyses $[2,3]$, few studies systematically reported the frequency of infections in COVID-19 patients, and fewer described the microbiological pathogens or methods used to detect the pathogens. The meta-analyses were based on 28 ( $n=$
3448 patients) [3] and 30 studies ( $n=3834$ patients) [2], respectively. Overall, 7\% of hospitalized COVID-19 patients had a bacterial infection, with a higher proportion of infections among ICU patients than mixed patients ( $14 \%$ vs. $4 \%)$ [2]. Overall, it was unclear whether reported infections were community- or hospital-acquired, and the proportion differed according to the reported method of testing ( $4 \%$ and $10 \%$ by culture and unspecified methods, respectively) [3]. Bacterial species were reported in only 13 ( $n=41$ bacteria) and 17 studies $(n=$ 27 bacteria), respectively-highlighting the lack of standardized sampling and reporting of bacterial superinfections among COVID-19 patients [16]. Viral co-infections 
were reported in less than $2 \%$ of SARS-CoV-2-positive patients [5, 9]. After publication of the meta-analyses, studies from Spain, France, and the UK have shed some more light onto occurrence of community- and hospitalacquired infections among hospitalized patients [4-6]. In agreement with our findings, viral co-infections and community-acquired bacterial pneumonias were rarely diagnosed $(2-3 \%)[4,5]$. Though based on low absolute numbers, the causative pathogens reported included the usual causes of community-acquired pneumonia such as Streptococcus pneumoniae, Staphylococcus aureus, and Haemophilus influenzae. By contrast, the risk of late bacterial infection seems to exceed a much greater problem among hospitalized patients. Among 989 Spanish COVID-19 pneumonia patients, 73 patients had a microbiologically confirmed infection, counting 74 bacterial infections (e.g. pneumonia, bacteraemia, urinary tract, and intraabdominal infection), seven fungal and seven viral infections. Diagnosis of bacterial infections was performed with urinary antigen tests in 12 patients, and culture in only three patients. The Spanish study identified 15 bacterial and three Aspergillus fumigatus hospitalacquired pulmonary infections including 11 VAPs. Among 54 French ICU patients, 20 (37\%) had a bacterial pneumonia, of which 15 cases were ventilator-associated and mainly with late-onset [17]. The causative pathogens of hospital-acquired infections included both Staphylococcus aureus, as well as different Enterobacteriaceae and non-fermenters, generally known to be frequent courses of VAP [18]. Whereas studies reporting laboratory-detected pathogens found Mycoplasma pneumonia to constitute $29 \%$ and $42 \%$ of pathogens detected (unclear if results were based on serology or PCR), we did not detect any co-infection with these pathogens or Legionella pneumophila in our cohort. A US cohort of 5700 patients detected only three patients with Chlamydia pneumoniae or Mycoplasma pneumoniae, but completeness of testing was unknown [19]. Disseminated aspergillosis cases among COVID-19 patients have been described [20,21], but the difficulty of the diagnosis also highlighted [22]. In our cohort, one had autopsy-proven disseminated aspergillosis and another suspected aspergillosis (clinical suspicion together with a positive culture and Aspergillus-specific PCR). Both patients showed a respiratory deterioration before microbiological diagnosis of aspergillosis, and none of them were immunosuppressed or received tocilizumab. We found that patients frequently were colonized with Candida species, but these were not considered to play a direct role as VAP-causative pathogen [18]. Bloodstream infection may also complicate the clinical course in hospitalized COVID-19 pneumonia patients. Among 227 Danish patients, none had community-acquired bloodstream infection, whereas $12(5.3 \%)$ had a hospital-acquired bloodstream infection. In comparison, the proportion of patients with bloodstream infection was $1.4 \%$ in a matched cohort of patients without COVID-19 pneumonia [7]. In an Italian study of 78 critically ill COVID-19 patients, $31(40 \%)$ had at least one bloodstream infection, adding to a cumulative risk of $25 \%$ after 15 days of admission [8]. In agreement, we found only one community-acquired bloodstream infection, whereas $10 \%$ of ICU patients had a hospital-acquired bloodstream infection. Whereas we found only one multidrug resistant pathogen, nine multi-drug resistant pathogens were detected in the Spanish cohort [5], stressing the need for microbiological testing in order to guide antibiotic treatment.

Duration of symptoms before hospitalization among patients requiring ICU admission was similar to other hospitalized patients, whereas the excluded patients had shorter symptom duration. Patients requiring ICU admission had a twice as long hospitalization than the overall cohort did, and a high proportion of ICU patients needed mechanical ventilation. Overall, mortality in our study and the Spanish cohort was comparable. The Spanish study concluded that patients with hospital-acquired superinfection had a longer stay and higher mortality (using significance testing) [5]. We refrained from significance testing because question on causality is difficult. Did patients have longer hospitalization durations because of secondary infections, or were secondary infections a consequence of a prolonged hospital duration?

The pooled estimate of supplementary antibiotics among COVID-19 patients was $72 \%$ in the meta-analysis (based on 14 studies, $n=1689$ patients) [3]. The substantial use of antibiotics may reflect that the clinical assessment is complex, especially in the situation of a previously unknown pathogen, where the natural course of, e.g. inflammatory markers is unknown. The fear of bacterial secondary infections may have led to unnecessary empiric broad-spectrum antibiotic therapy. In our cohort, fewer patients than previously reported received antibiotic therapy. Still, not all had culture-proven infections, and importantly, also the majority of ICU patients without clinical signs of bacterial or fungal infections were treated with antibiotics. Overall, empirical use of antibiotics was lower among patients treated at the general medical ward, where procalcitonin was used to guide antibiotic treatment among patients. However, procalcitonin and other inflammatory markers were not relied on in the discrimination between superinfections and cytokine storm among ICU patients, which may explain the substantial overuse of antibiotics in this setting.

Bacterial pneumonia is a frequent complication in patients with respiratory viral infections. For Influenza virus A, up to $35 \%$ of patients are diagnosed community-acquired bacterial pneumonia, mainly 
caused by Streptococcus pneumoniae and Staphylococcus aureus [23-26]. For COVID-19 pneumonia, the rate of community-acquired bacterial pneumonia seems to be lower. We found a higher occurrence of VAP in our cohort than reported in the Spanish cohort of COVID-19 patients (5 of $41(12.2 \%)$ vs. 11 of $146(7.5 \%))$, pathogens in both cohorts mainly constituted by gram-negative bacteria. Importantly, Aspergillus fumigatus is a serious and non-negligible cause of severe VAP, occurring in around $20 \%$ of ICU patients with influenza-associated pulmonary infections $[27,28]$. In the Spanish cohort, there were three cases of hospital-acquired infections caused by aspergillosis, and in our cohort two cases. Though it is yet not clear how often aspergillosis complicates the course of COVID-19 pneumonia, several centres have reported cases of disseminated aspergillosis among patients.

A strength of our study is the structured interdisciplinary assessment, combining the microbial findings with the clinical presentation. We provide detailed information on the completeness of testing, the laboratory detection of pathogens, and diagnostic criteria. We observed a low rate of community-acquired respiratory viral co-infections, which may be indicative competitive infection situation for viruses targeting the respiratory tract [9]. Atypical bacterial pneumonia was also rare-but is known to most often affect younger adults-and median age in our cohort was 64 years. However, we found that bacterial and fungal secondary infections occurred more often among patients requiring ICU admission than reported in the meta-analysis and the Spanish cohort [5]. The difference may be explained by our restriction to SARSCoV-2-positive patients with COVID-19 pneumonia (i.e. not only SARS-CoV-2 positive). While most ICU patients had respiratory samples for culture, we may have missed relevant pathogens, when sampling was performed after initiation of antibiotics. In our cohort, the use of antibiotics was lower than reported in the meta-analyses, but still higher than necessary after retrospective evaluation, stressing the need for antibiotic stewardship even in difficult times of a pandemic. Unnecessary antibiotic treatment is crucial to circumvent development of antimicrobial resistance, in addition to other collateral damages such as colonization with resistant pathogens or antibioticassociated infections, e.g. Clostridioides difficile.

\section{Conclusion}

We observed a high frequency of secondary infections among hospitalized SARS-CoV-2-positive patients requiring ICU admission, which complicated the already challenging clinical management of the patients.

\section{Supplementary Information}

The online version contains supplementary material available at https://doi. org/10.1186/s40560-021-00526-y.

\section{Additional file 1.}

Abbreviations

ARDS: Acute respiratory distress syndrome; COVID-19: Coronavirus disease; ECMO: Extracorporeal membrane oxygenation; HAP: Hospital-acquired pneumonia; ICU: Intensive care unit; IQR: Interquartile range; PCR: Polymerase chain reaction; SARS-CoV-2: Severe acute respiratory syndrome coronavirus 2; VAP: Ventilator-associated pneumonia

\section{Acknowledgements}

We thank Clarisse Straub and Dr. Tim Roloff (University Hospital Basel) for excellent technical assistance with extracting data.

\section{Authors' contributions}

KKS and AE designed the study. KKS, MS, VB, and MSch collected the data. KKS performed the analysis. KKS drafted the report. All authors contributed to the intellectual content and have seen and approved the final version of the manuscript.

Funding

None

Availability of data and materials

The data used and analysed for this study are available from the corresponding author on reasonable request.

Ethics approval and consent to participate

The local ethics committee approved the study (EKNZ project ID 2020-

00769). Patients who declined the general consent were not included.

Consent for publication

Not applicable.

\section{Competing interests}

The authors declare no competing interest.

\section{Author details}

${ }^{1}$ Clinical Bacteriology and Mycology, University Hospital Basel, Petersgraben 4, 4031 Basel, Switzerland. ²Department of Biomedicine, Applied

Microbiology Research, University of Basel, Basel, Switzerland. ${ }^{3}$ Division of Infectious Diseases \& Hospital Epidemiology, University Hospital Basel and University of Basel, Basel, Switzerland. ${ }^{4}$ Division of Internal Medicine, University Hospital Basel, Basel, Switzerland. ${ }^{5}$ Department of Clinical Research, University Hospital Basel, Basel, Switzerland. ${ }^{6}$ Department of Intensive Care Medicine, University Hospital Basel, Basel, Switzerland. ${ }^{7}$ Clinical Virology, Laboratory Medicine, University Hospital Basel, Basel, Switzerland. ${ }^{8}$ Hospital Pharmacy, University Hospital Basel, Basel, Switzerland. ${ }^{9}$ Department of Emergency Medicine, University Hospital Basel, Basel, Switzerland.

${ }^{10}$ Transplantation \& Clinical Virology, Department of Biomedicine, University of Basel, Basel, Switzerland.

Received: 19 October 2020 Accepted: 6 January 2021

Published online: 18 January 2021

\section{References}

1. Wu CP, Adhi F, Highland K. Recognition and management of respiratory coinfection and secondary bacterial pneumonia in patients with COVID-19: Posted april 27, 2020. Cleve Clin J Med. 2020;87(11):659-63.

2. Lansbury L, Lim B, Baskaran V, Lim WS. Co-infections in people with COVID19: a systematic review and meta-analysis. J Infect. 2020;81(2):266-75.

3. Langford BJ, So M, Raybardhan S, Leung V, Westwood D, MacFadden DR, et al. Bacterial co-infection and secondary infection in patients with COVID19: a living rapid review and meta-analysis. Clin Microbiol Infect. 2020;26(12): 1622-9.

4. Hughes S, Troise O, Donaldson H, Mughal N, Moore LSP. Bacterial and fungal coinfection among hospitalized patients with COVID-19: a 
retrospective cohort study in a UK secondary-care setting. Clin Microbio Infect. 2020;26(10):1395-9.

5. Garcia-Vidal C, Sanjuan G, Moreno-García E, Puerta-Alcalde P, Garcia-Pouton $\mathrm{N}$, Chumbita $\mathrm{M}$, et al. Incidence of co-infections and superinfections in hospitalised patients with COVID-19: a retrospective cohort study. Clin Microbiol Infect. 2020. https://doi.org/10.1016/j.cmi.2020.07.041.

6. Contou D, Claudinon A, Pajot O, Micaëlo M, Longuet Flandre P, Dubert $M$, et al. Bacterial and viral co-infections in patients with severe SARSCoV-2 pneumonia admitted to a French ICU. Ann Intensive Care. 2020 10(1):119.

7. Engsbro AL, Israelsen SB, Pedersen M, Tingsgaard S, Lisby G, Andersen CØ, Benfield T. Predominance of hospital-acquired bloodstream infection in patients with Covid-19 pneumonia. Infect Dis. 2020;52:919-22.

8. Giacobbe DR, Battaglini D, Ball L, Brunetti I, Bruzzone B, Codda G, et al. Bloodstream infections in critically ill patients with COVID-19. Eur J Clin Investig. 2020;50(10):e13319.

9. Leuzinger K, Roloff T, Gosert R, et al. Epidemiology of SARS-CoV-2 emergence amidst community-acquired respiratory viruses. J Infect Dis. 2020;222(8):1270-9.

10. Osthoff M, Gürtler N, Bassetti S, Balestra G, Marsch S, Pargger H, et al. Impact of MALDI-TOF-MS-based identification directly from positive blood cultures on patient management: a controlled clinical trial. Clin Microbiol Infect. 2017;23:78-85.

11. Metlay JP, Waterer GW, Long AC, Anzueto A, Brozek J, Crothers K, et al. Diagnosis and treatment of adults with community-acquired pneumonia. Am J Respir Crit Care Med. 2019;200:e45-67.

12. Magill SS, Klompas M, Balk R, Burns SM, Deutschman CS, Diekema D, et al. Developing a new, national approach to surveillance for ventilatorassociated events. Crit Care Med. 2013;41:1096-9.

13. Feng $Y$, Ling $Y$, Bai T, et al. COVID-19 with different severities: a multicenter study of clinical features. Am J Respir Crit Care Med. 2020;201:1380-8.

14. Lippi G, Mattiuzzi C, Sanchis-Gomar F, Henry BM. Clinical and demographic characteristics of patients dying from COVID-19 in Italy versus China. J Med Virol. 2020. https://doi.org/10.1002/jmv.25860.

15. Li LQ, Huang T, Wang YQ, Wang ZP, Liang Y, Huang TB, Zhang HY, Sun W, Wang Y. COVID-19 patients' clinical characteristics, discharge rate, and fatality rate of meta-analysis. J Med Virol. 2020;92(6):577-83.

16. Clancy CJ, Nguyen MH. COVID-19, superinfections and antimicrobial development: What can we expect? Clin Infect Dis. 2020. https://doi.org/10. 1093/cid/ciaa524.

17. Dudoignon E, Caméléna F, Deniau B, Habay A, Coutrot M, Ressaire Q, et al. Bacterial Pneumonia in COVID-19 critically ill patients: a case series. Clin Infect Dis. 2020:ciaa762. https://doi.org/10.1093/cid/ciaa762.

18. Papazian L, Klompas M, Luyt CE. Ventilator-associated pneumonia in adults: a narrative review. Intensive Care Med. 2020;46:888-906.

19. Richardson S, Hirsch JS, Narasimhan M, Crawford JM, McGinn T, Davidson $\mathrm{KW}$, et al. Presenting characteristics, comorbidities, and outcomes among 5700 patients hospitalized with COVID-19 in the New York City area. JAMA J Am Med Assoc. 2020;323:2052-9.

20. Rutsaert L, Steinfort N, Van Hunsel T, Bomans P, Naesens R, Mertes H, et al. COVID-19-associated invasive pulmonary aspergillosis. Ann Intensive Care. 2020;10:71.

21. Alanio A, Dellière $S$, Fodil $S$, Bretagne $S$, Mégarbane B. High prevalence of putative invasive pulmonary aspergillosis in critically ill COVID-19 patients. Lancet Respir Med. 2020;8(6):e48-9. https://doi.org/10.1016/S22132600(20)30237-X.

22. Fekkar A, Poignon C, Blaize M, Lampros A. Fungal infection during COVID19: does Aspergillus mean secondary invasive aspergillosis? Am J Respir Crit Care Med. 2020. https://doi.org/10.1164/rccm.202005-1945LE.

23. Blyth CC, Webb SAR, Kok J, Dwyer DE, van Hal SJ, Foo H, et al. The impact of bacterial and viral co-infection in severe influenza. Influenza Other Respir Viruses. 2013;7:168-76.

24. Martín-Loeches I, Sanchez-Corral A, Diaz E, Granada RM, Zaragoza R, Villavicencio C, et al. Community-acquired respiratory coinfection in critically III patients with pandemic 2009 influenza A(H1N1) virus. Chest. 2011;139: $555-62$

25. Rice TW, Rubinson L, Uyeki TM, Vaughn FL, John BB, Miller RR, et al. Critical illness from 2009 pandemic influenza A virus and bacterial coinfection in the United States. Crit Care Med. 2012;40:1487-98.

26. Chertow DS, Memoli MJ. Bacterial coinfection in influenza: a grand rounds review. JAMA - J Am Med Assoc. 2013;309:275-82.
27. Wauters J, Baar I, Meersseman P, Meersseman W, Dams K, De Paep R, et al. Invasive pulmonary aspergillosis is a frequent complication of critically ill H1N1 patients: A retrospective study. Intensive Care Med. 2012;38:1761-8.

28. Beumer MC, Koch RM, van Beuningen D, OudeLashof AM, van de Veerdonk FL, Kolwijck E, et al. Influenza virus and factors that are associated with ICU admission, pulmonary co-infections and ICU mortality. J Crit Care. 2019;50: 59-65.

\section{Publisher's Note}

Springer Nature remains neutral with regard to jurisdictional claims in published maps and institutional affiliations.
Ready to submit your research? Choose BMC and benefit from:

- fast, convenient online submission

- thorough peer review by experienced researchers in your field

- rapid publication on acceptance

- support for research data, including large and complex data types

- gold Open Access which fosters wider collaboration and increased citations

- maximum visibility for your research: over $100 \mathrm{M}$ website views per year

At $\mathrm{BMC}$, research is always in progress.

Learn more biomedcentral.com/submissions 